\title{
Comparison of dexmedetomidine and epinephrine as an adjuvant to $1 \%$ mepivacaine in brachial plexus block
}

\author{
Jang-Ho Song ${ }^{1}$, Hee Yong Shim ${ }^{1}$ Tong Joo Lee ${ }^{2}$, Jong-Kwon Jung ${ }^{1}$, Young-Deog Cha ${ }^{1}$, Doo Ik Lee ${ }^{1}$, \\ Gun Woo Kim ${ }^{1}$, and Jeong Uk Han ${ }^{1}$ \\ Departments of ${ }^{1}$ Anesthesiology and Pain Medicine, ${ }^{2}$ Orthopedic Surgery, Inha University School of Medicine, Incheon, Korea
}

Background: Dexmedetomidine extends the duration of nerve block when administered perineurally together with local anesthetics by central and/or peripheral action. In this study, we compared the duration of nerve block between dexmedetomidine and epinephrine as an adjuvant to $1 \%$ mepivacaine in infraclavicular brachial plexus block.

Methods: Thirty patients, scheduled for upper limb surgery were assigned randomly to 3 groups of 10 patients each. We performed brachial plexus block using a nerve stimulator. In the control group (group C), patients received $40 \mathrm{ml}$ of $1 \%$ mepivacaine. In group E, patients received $40 \mathrm{ml}$ of $1 \%$ mepivacaine containing $200 \mu \mathrm{g}$ of epinephrine as an adjuvant. In group $\mathrm{D}$, patients received $40 \mathrm{ml}$ of $1 \%$ mepivacaine containing $1 \mu \mathrm{g} / \mathrm{kg}$ of dexmedetomidine as an adjuvant. Sensory block duration, motor block duration, time to sense pain, and onset time were assessed. We also monitored blood pressure, heart rate, oxygen saturation and bispectral index.

Results: In group D and group E, sensory block duration, motor block duration and time to sense first pain were prolonged significantly compared to group C. However, there was no significant difference between group D and group E.

Conclusions: Perineural $1 \mu \mathrm{g} / \mathrm{kg}$ of dexmedetomidine similarly prolonged nerve block duration compared to $200 \mu \mathrm{g}$ of epinephrine, but slowed heart rate. Thus, dexmedetomidine is expected to be a good alternative as an adjuvant to local anesthesia in patients who are cautioned against epinephrine. (Korean J Anesthesiol 2014; 66: 283-289)

Key Words: Brachial plexus, Dexmedetomidine, Epinephrine.

Received: September 3, 2013. Revised: 1st, October 3, 2013; 2nd, October 10, 2013. Accepted: October 14, 2013.

Corresponding author: Jeong Uk Han, M.D., Department of Anesthesiology and Pain Medicine, Inha University School of Medicine, Inha University Hospital, Sinheung-dong 3-ga, Jung-gu, Incheon 400-711, Korea. Tel: 82-32-890-3968, Fax: 82-32-881-2476, E-mail: jwhanan@nate.com (c) This is an open-access article distributed under the terms of the Creative Commons Attribution Non-Commercial License (http:// creativecommons.org/licenses/by-nc/3.0/), which permits unrestricted non-commercial use, distribution, and reproduction in any medium, provided the original work is properly cited. 


\section{Introduction}

Dexmedetomidine, a selective $\alpha-2$ agonist that works on the central nervous system, has the effects of lowering blood pressure, sedation, sleep, analgesia, memory loss, and decreased shivering. Recently, its use has increased in the intensive care uint for sedation purposes, general anesthesia, various tests and as an adjuvant to regional anesthesia [1-3]. Many studies have reported that dexmedetomidine extends the duration of nerve block when administered perineurally together with local anesthetics [4,5]. Brummett et al. [4] reported that dexmedetomidine administered with bupivacaine in sciatic nerve block of a mouse resulted in extended sensory nerve block and motor nerve block without nerve toxicity. Esmaoglu et al. [5] reported that the addition of dexmedetomidine to axillary brachial plexus block resulted in a shorter onset time of the nerve block, an extended duration, and a longer postoperative painless period. This is assumed to be the central effect of dexmedetomidine [6] or its local effect influencing the mechanism of local anesthetics [7-12]. In particular, the vasoconstrictor effect on the periphery is also considered to have an effect [7-10].

Epinephrine, a vasoconstrictor, reduces absorption into the bloodstream when used as an adjuvant to local anesthetics. Therefore, it reduces the systemic toxicity of local anesthetics and extends the duration of anesthesia. It is also widely used for early differentiation of intravascular absorption [13]. However, it can cause hypertension, tachycardia, and arrhythmia, and it can worsen symptoms in patients with accompanying coronary artery disease. Such systemic complications can be especially severe when the drug is unintentionally absorbed intravenously. Therefore, caution is required when using epinephrine as an adjuvant in patients with hyperthyroidism or cardiovascular diseases such as severe hypertension, arrhythmia, and tachycardia [14].

This study compared using $1 \mu \mathrm{g} / \mathrm{kg}$ of dexmedetomidine as an adjuvant to local anesthesia with using $200 \mu \mathrm{g}$ of epinephrine to assess the degree to which each extended the nerve block duration and to judge whether dexmedetomidine can serve as an alternative to epinephrine when necessary. The concentration of epinephrine used in this research was $1: 200,000$, which is the amount generally used to achieve a vasoconstriction effect as an adjuvant to local anesthesia [14]. In the case of dexmedetomidine, because no studies comparing it with epinephrine as an adjuvant could be found, the amount used in several studies, $1 \mu \mathrm{g} / \mathrm{kg}$, was chosen [15-17]. This amount is loading dose for the first 10 minutes in generalized intravenous (IV) infusion method, and thus this amount was assumed to have no complications when injected suncutaneously.

\section{Materials and Methods}

This research involved 30 patients aged 18-65 years of American Society of Anesthesiologists (ASA) physical status class 1 or 2 who were scheduled for upper limb surgery and brachial plexus block. The study was approved by the Institutional Review Board at our hospital, and the purpose of the study was explained to the patients to obtain their consent before participation. Patients who were obese (body mass index $>35 \mathrm{~kg} / \mathrm{m}^{2}$ ) or pregnant and those with a liver function or kidney function disorder, diabetic neuropathy, a coagulopathy, a history of taking a-2 adrenergic drugs in the previous 2 weeks, clinically significant arrhythmia, or an infectious lesion in the puncture site were excluded from the research.

No patients received premedication. Just before arrival in the operating room, the computer randomly assigned patients to the control group (group C), the epinephrine group (group E), or the dexmedetomidine group (group D). After arrival in the operating room, a non-invasive blood pressure monitor and pulse oximeter were attached to the upper arm on the side opposite to the operating area, and a bispectral index (BIS) sensor was attached to the forehead. A skilled anesthesiologist performed the infraclavicular brachial plexus block. The patient was placed in the supine position with the head turned to face the side opposite the operating area, and the upper arm to be operated was put on top of the abdomen. The needle insertion site was the center of the line connecting the jugular fossa and ventral process of the acromion. A 22-gauge, 50-mm short-beveled needle (Stimuplex ${ }^{\circledR}$ A, B/Braun, Melsungen, Germany) and nerve stimulator (Stimuplex ${ }^{\circledR}$-DIG, B/Braun, Melsungen, Germany) were used to check the nerve plexus. Starting with a stimulus of $1 \mathrm{~Hz}, 1.0 \mathrm{~mA}$, the size of the current was decreased, and when finger flexion was observed at a minimum $0.4 \mathrm{~mA}$ or lower, the prepared drug for each group was administered.

Group C was administered normal saline $20 \mathrm{ml}$, group E was administered a combination of $200 \mu \mathrm{g}$ epinephrine (Daihan Pharm Co, Seoul, Korea) diluted to $1 \mathrm{ml}$ and normal saline $19 \mathrm{ml}$, and group D was administered a $20 \mathrm{ml}$ solution combining normal saline with $1 \mu \mathrm{g} / \mathrm{kg}$ dexmedetomidine (Precedex ${ }^{\circledR}$ Hospira, Lake Forest, IL, USA) diluted to $4 \mu \mathrm{g} / \mathrm{ml}$. In addition, $2 \%$ mepivacaine (Emcaine $2 \%{ }^{\circledR}$ Reyon Pharm Co, Seoul, Korea) $20 \mathrm{ml}$ was added to all groups to achieve a total of $40 \mathrm{ml}$.

Directly after drug administration, the breathing rate was monitored while oxygen at $5 \mathrm{~L} / \mathrm{min}$ was supplied through an oxygen mask. The level of sensory and motor block was evaluated every 2 minutes after drug administration.

The level of sensory block was assessed by performing the pinprick test on the back of the hand for the radial nerve, the fifth finger for the ulnar nerve, and the third finger for the median nerve. A score of 0 points was assigned when there was no 
difference in pain compared to the opposite side, 1 point when there was less pain, and 2 points when there was no pain at all. The level of motor block was evaluated by thumb abduction for the radial nerve, thumb adduction or spreading for the ulnar nerve, and the strength of thumb opposition for the median nerve. A score of 0 points was assigned when there was no difference in strength compared to the opposite side, 1 point when the strength was decreased, and 2 points when there was complete motor block [18].

Successful brachial plexus block was defined as follows: for sensory nerves, 2 points each in the radial nerve, ulnar nerve, and median nerve; for motor nerves, 1 point or more in each of the 3 nerves.

Blood pressure, heart rate, pulse oximetry, and BIS were measured every 5 minutes for 1 hour after administering the drugs. To assess the sedative effect of dexmedetomidine, the patient was observed without any administration of sedative for the first 30 minutes. When the BIS was 80 or higher 30 minutes after drug administration, midazolam 2-3 mg was IV injected to provide sedation, and $1 \mathrm{mg}$ was additionally administered to achieve a BIS range of $60-80$. If pulse oximetry was $95 \%$ or if the breathing rate was 10 times or fewer during surgery, the neck was to be extended; if the extension did not achieve the required adjustment, supplementary mask ventilation would be performed. In the event of bradycardia, a heart rate of 50 beats or fewer per minute, glycopyrrolate $0.2 \mathrm{mg}$ was to be IV injected. When mean arterial pressure was $50 \mathrm{mmHg}$ or less or decreased $20 \%$ or more from the baseline value, ephedrine $4 \mathrm{mg}$ was to be IV injected to correct the vital signs.

The time to recovery from sensory nerve and motor nerve block, the time to the first sensation of pain, and the VAS score at that time were recorded by a single examiner at 30 minute intervals starting from 120 minutes after the successful brachial plexus block.

The duration of sensory nerve block was defined as the period from successful block until all senses controlled by the radial, ulnar, and median nerves were completely restored. The duration of motor nerve block was defined as the period from successful block until the strength of the radial, ulnar, and me- dian nerves were completely restored.

In a preliminary study conducted with 4 control group patients, 5 epinephrine group patients, and 5 dexmedetomidine group patients, the mean values and standard deviations of the sensory nerve block durations were $226 \pm 64 \mathrm{~min}, 295 \pm 11 \mathrm{~min}$, and $367 \pm 49 \mathrm{~min}$, respectively. The standard deviation of the entire sample was 72 . Assuming that 80 is the maximum standard deviation, 8 subjects are needed for each group at $\alpha$ value 0.05 and $\beta$ value 0.2 . Considering a $20 \%$ dropout rate to account for factors such as failure of brachial plexus anesthesia, it was determined that each group should have 10 subjects, meaning 30 subjects in total.

Sigmaplot ${ }^{\circledR}$ Version 12 (Systat Software Inc., San Jose, CA, USA) was used for statistical analysis. All variables were expressed as the mean \pm standard deviation. Kruskal-Wallis one way ANOVA on ranks was used to compare groups, and the post-hoc test or multiple comparison method was conducted with the Tukey test. The mean arterial pressure, heart rate, and BIS compared to baseline values over time were analyzed within each group using repeated measures ANOVA on ranks, and then the Holm-Sidak method was used as a post-hoc test or multiple comparison method. A comparison regarding the use of midazolam was performed with Fisher's exact test. A P value of less than 0.05 was considered statistically significant.

\section{Results}

Brachial plexus block was successful in all 30 patients. There were no significant differences between the 3 groups in terms of age, sex, height, weight, and ASA physical status (Table 1). Among the 30 patients, 9 were scheduled for fracture surgery, 3 were scheduled for surgery to remove internal fixation devices after fractures, 11 were scheduled for injury-related surgery other than fracture surgery, and 7 were scheduled for surgery related to disease rather than injury. In terms of the surgical area, 13 patients were scheduled to receive surgery of the hand area or lower, 5 of the wrist joint, 9 of the forearm, and 3 of the elbow joint.

With regard to brachial plexus block, the duration of sensory

Table 1. Demographic Characteristics and Surgical Sites

\begin{tabular}{lccc}
\hline & Group C $(\mathrm{n}=10)$ & Group E $(\mathrm{n}=10)$ & Group D (n=10) \\
\hline Age $(\mathrm{yr})$ & $48.0 \pm 13.7$ & $39.5 \pm 13.5$ & $38.0 \pm 13.4$ \\
Sex $(\mathrm{M} / \mathrm{F})$ & $8 / 2$ & $8 / 2$ & $8 / 2$ \\
Height $(\mathrm{cm})$ & $165.3 \pm 7.9$ & $168.9 \pm 10.9$ & $169.8 \pm 8.9$ \\
Weight $(\mathrm{kg})$ & $68.4 \pm 9.8$ & $65.5 \pm 14.5$ & $64.8 \pm 9.6$ \\
ASA physical status (I/II) & $4 / 6$ & $6 / 4$ & $3 / 7$ \\
Surgical sites (H/W/F/E) & $3 / 3 / 4 / 0$ & $5 / 0 / 3 / 2$ & $4 / 2 / 3 / 1$ \\
\hline
\end{tabular}

Values presented as the mean \pm SD or numbers. Group C: control group, Group E: epinephrine group, Group D: dexmedetomidine group. H: hand, W: wrist, F: forearm, E: elbow. 
Table 2. Duration of Sensory Block and Motor Block and Time to Sense First Pain

\begin{tabular}{lccc}
\hline & Group C $(\mathrm{n}=10)$ & Group E $(\mathrm{n}=10)$ & Group D (n=10) \\
\hline Onset time (min) & $9.0 \pm 3.7$ & $9.6 \pm 4.3$ & $10.4 \pm 3.1$ \\
Sensory Block (min) & $289.7 \pm 52.9$ & $353.5 \pm 53.4^{*}$ & $367.9 \pm 35.8^{*}$ \\
Motor Block (min) & $283.7 \pm 43.7$ & $334.3 \pm 46.5^{*}$ & $349.9 \pm 28.2^{*}$ \\
Time to Sense First Pain (min) & $295.7 \pm 52.1$ & $349.3 \pm 50.5^{*}$ & $358.9 \pm 36.2^{*}$ \\
\hline
\end{tabular}

Values presented as the mean \pm SD. Group C: control group, Group E: epinephrine group, Group D: dexmedetomidine group. ${ }^{*} \mathrm{P}<0.05$ compared to group C.

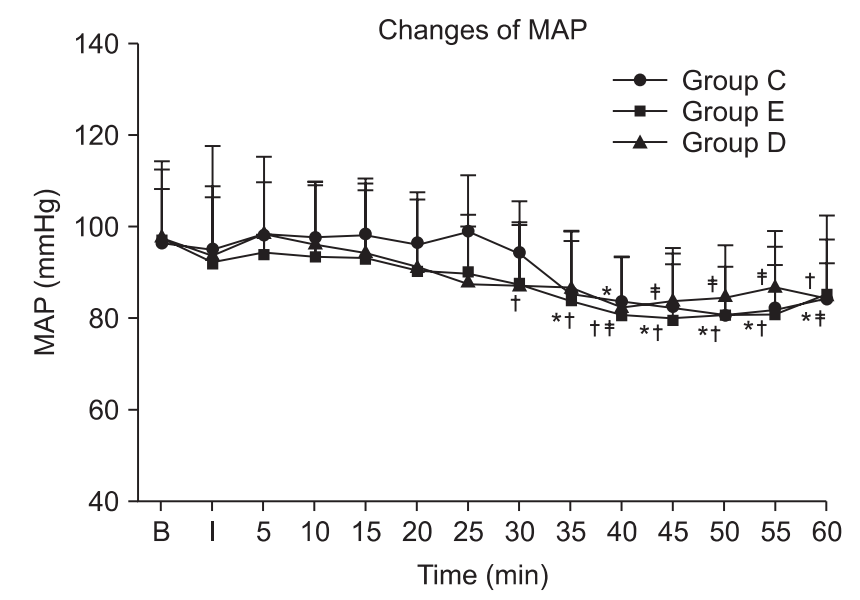

Fig. 1. The mean arterial pressure (MAP) for the three groups in consecutive periods. There are no significant differences between the groups at each time. ${ }^{*} \mathrm{P}<0.05$ compared to baseline value in group $\mathrm{C}$. ${ }^{+} \mathrm{P}<0.05$ campared to baseline value in group $\mathrm{E} .{ }^{\ddagger} \mathrm{P}<0.05$ compared to baseline value in group $\mathrm{D}$. Values are expressed as the mean $\pm \mathrm{SD}$. B: baseline, I: just after brachial plexus block, min: minutes, Group C: control group, Group E: epinephrine group, Group D: Dexmedetomidine group.

and motor nerve block was significantly extended in group $\mathrm{D}$ and group $\mathrm{E}$ compared to group $\mathrm{C}(\mathrm{P}<0.05)$, but there was no significant difference between group $\mathrm{D}$ and group $\mathrm{E}$ (Table 2 ).

The time from brachial plexus block to first pain sensation was also significantly longer in group $\mathrm{D}$ and group $\mathrm{E}$ compared to group $\mathrm{C}(\mathrm{P}<0.05)$, but there was no significant difference between group $\mathrm{D}$ and group $\mathrm{E}$ (Table 2).

No significant difference between the 3 groups was found in the onset time of complete block (Table 2). The mean VAS score at the time of first pain sensation was $4.7 \pm 1.3 \mathrm{~min}, 4.5 \pm$ $0.5 \mathrm{~min}$, and $4.2 \pm 0.4 \mathrm{~min}$ in group $\mathrm{C}$, group $\mathrm{D}$, and group $\mathrm{E}$, respectively, and there was no statistically significant difference.

There was no significant difference in mean arterial pressure between the 3 groups, but in all groups, a decrease was observed after 30 minutes compared to the baseline $(\mathrm{P}<0.05)$ (Fig. 1). the heart rate was significantly lower in group $\mathrm{D}$ compared to group $\mathrm{E}$ at 20,30, 35, and 40 minutes after drug administration $(\mathrm{P}<0.05)$ (Fig. 2). It was also significantly lower than group $\mathrm{C}$ at 40 minutes after drug administration $(\mathrm{P}<0.05)$ (Fig. 2$)$. In

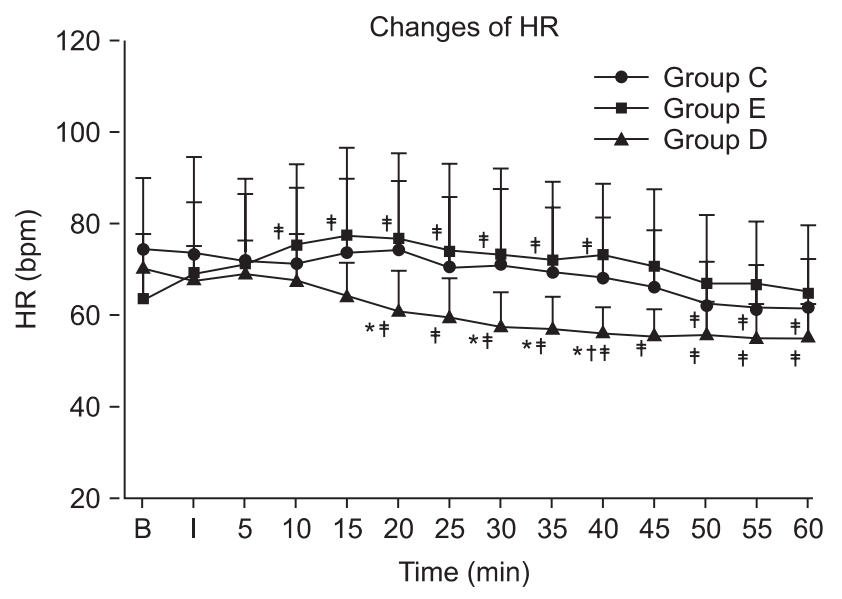

Fig. 2. The heart rate (HR) for the three groups in consecutive periods. Heart rate was significantly lower in group D compared to group $\mathrm{E}$ in 20 minutes, 30 minutes, 35 minutes and 40 minutes after drug injection. And in group D, heart rate was significantly lower compared to group $\mathrm{C}$ in 40 mimutes after drug injection. Values are expressed as mean \pm $\mathrm{SD} . * \mathrm{P}<0.05$ compared to group $\mathrm{E}$ in each time. ${ }^{\dagger} \mathrm{P}<0.05$ compared to group $\mathrm{C} .{ }^{\ddagger} \mathrm{P}<0.05$ compared to baseline value in each groups. $\mathrm{B}$ : baseline, I: just after brachial plexus block, min: minutes, bpm: beats per minutes, Group C: control group, Group E: epinephrine group, Group D: Dexmedetomidine group.

addition, in group $\mathrm{E}$, the HR increased from 10 to 40 minutes after drug administration compared to baseline $(\mathrm{P}<0.05)$. In group D, the HR decreased from 20 to 60 minutes after drug administration compared to baseline $(\mathrm{P}<0.05)$, while in group $\mathrm{C}$, it decreased starting at 50 minutes after drug administration. No patients in this study required ephedrine administration. The HR of 2 patients in group D fell to near 50, but there was no administration of glycopyrrolate.

There was no significant difference in BIS scores between group $\mathrm{C}$ and group $\mathrm{E}$ during the entire period, but group D had significantly lower BIS scores than group $\mathrm{C}$ at $15,20,25$, $30,35,40$, and 60 minutes after drug administration $(\mathrm{P}<0.05)$ (Fig. 3). In addition, group D had significantly lower BIS scores compared to group $\mathrm{E}$ at 15,35 , and 60 minutes after drug administration $(\mathrm{P}<0.05)$ (Fig. 3). All groups showed a significant decrease compared to baseline from 35 minutes to 60 minutes, which was after the administration of sedatives $(\mathrm{P}<0.05)$. Group D showed a significant decrease compared to baseline 


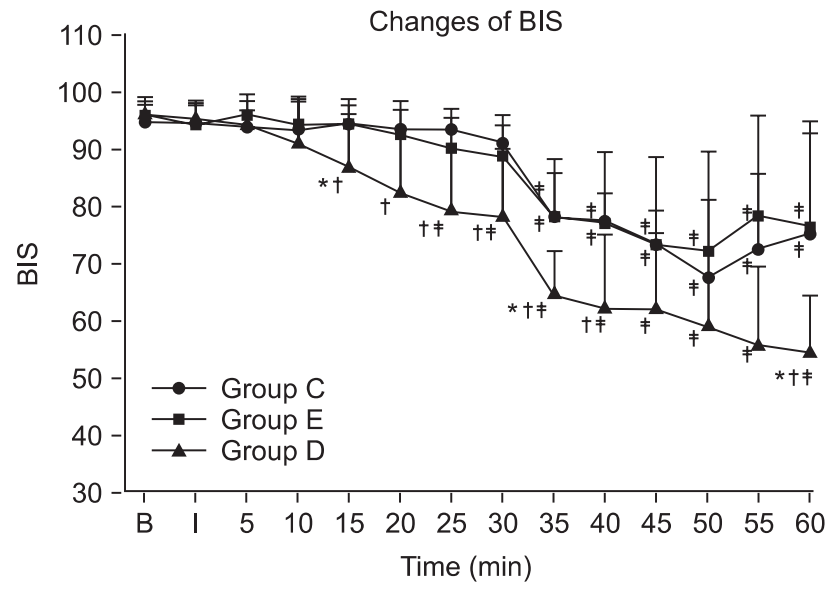

Fig. 3. The bispectral index (BIS) score for the three groups in consecutive periods. BIS was significantly lower in group D compared to group $\mathrm{C}$ in 15 minutes, 20 minutes, 25 minutes, 30 minutes, 35 minutes, 40 minutes and 60 minutes after drug injection. And in group D, BIS was significantly lower compared to group E in 15 mimutes, 35 minutes and 60 minutes after drug injection. Values are expressed as mean \pm SD. *P $<0.05$ compared to group $\mathrm{E}$ in each time. ${ }^{\dagger} \mathrm{P}<0.05$ compared to group C. ${ }^{\ddagger} \mathrm{P}<0.05$ compared to baseline value in each groups. B: baseline, I: just after brachial plexus block, min: minutes, Group C: control group, Group E: epinephrine group, Group D: Dexmedetomidine group.

at 25 minutes and 30 minutes after drug administration, before the administration of sedatives $(\mathrm{P}<0.05)$ (Fig. 3). At 30 minutes after drug administration, midazolam was administered to all patients in group $\mathrm{C}$ and group $\mathrm{E}$ for sedation, but only 3 patients in group $\mathrm{D}$ needed midazolam; there was a statistically significant difference $(\mathrm{P}<0.05)$. The amounts of midazolam used in each group were $2.6 \pm 0.52 \mathrm{mg}, 2.75 \pm 0.43 \mathrm{mg}$, and $0.90 \pm 1.45$ $\mathrm{mg}$ for group $\mathrm{C}$, group $\mathrm{E}$, and group $\mathrm{D}$, respectively. The amount used in group D was significantly lower compared to group $\mathrm{E}$ $(\mathrm{P}<0.05)$, but there was no difference with group $\mathrm{C}$.

\section{Discussion}

In this research, the groups that received either $1 \mu \mathrm{g} / \mathrm{kg}$ of dexmedetomidine or $200 \mu \mathrm{g}$ of epinephrine as an adjuvant to $1 \%$ mepivacaine $40 \mathrm{ml}$ both displayed an extended duration of sensory and motor block and time to sense first pain compared to the control group, which received only $1 \%$ mepivacaine 40 $\mathrm{ml}$. This accords with reports showing that dexmedetomidine extended the duration of brachial plexus or other local nerve blocks $[5,16,17]$, but there were no differences between the dexmedetomidine group and the epinephrine group.

In addition, no significant difference was found in the onset time between the 3 groups. Contrary to our findings, Esmaoglu et al. [5] reported that dexmedetomidine decreased the onset time in axillary brachial plexus block. Marhofer et al. [19] reported that it did not reduce the onset time but emphasized that this finding could have arisen because a nerve stimulator was used rather than an ultrasound. But, it is reported that the difference in methods of accessing to plexus does not affect onset time of nerve block [20]. A nerve stimulator was also used in our study, but there was no significant difference in the onset time, thus it is difficult to conclude that the block onset time is affected by the choice of nerve stimulator or ultrasound.

Dexmedetomidine can cause systemic effects such as sedation and relief of anxiety as well as complications such as hypotension and bradycardia as the dosage is increased [7]. In our research, there was no difference between the groups in mean arterial pressure, and in all groups, there was a decrease after 35 minutes compared to baseline values. This can be attributed to the influence of sedation, which was performed 30 minutes after drug administration. The heart rate decreased significantly in the dexmedetomidine group compared to the epinephrine group starting 20 minutes after drug administration, and even in the within-group comparison, the epinephrine group showed a significant increase compared to baseline starting 10 minutes after drug administration. The dexmedetomidine group, however, showed a significant decrease in heart rate compared to baseline starting 20 minutes after drug administration. In addition, to allow assessment of the sedative effect of dexmedetomidine, no sedatives were administered for 30 minutes after drug administration, but the BIS began to decrease in most of the subjects in the dexmedetomidine group around 15-20 minutes after drug administration. After 30 minutes, all patients in the control group and the epinephrine group required sedatives, but only 3 subjects in the dexmedetomidine group required sedatives. This finding accords with previous reports in which a $\alpha-2$ agonist used with local anesthesia had sedative effects. Gaumann et al. [21], using $150 \mu \mathrm{g}$ clonidine as an adjuvant to $1 \%$ lidocaine in brachial plexus block, reported a sedative effect lasting 60 minutes starting 30 minutes after administration. Rancourt et al. [15] and Swami et al. [16] also reported a sedative effect after administering dexmedetomidine perineurally. The analgesic effect of dexmedetomidine and the mechanism for sedation are not yet completely understood and are thought to arise from various factors. The drug is presumed to act centrally; it is thought that $\alpha-2$ agonists repress the secretion of substance $P$ in the pain transmission route at the dorsal root neuron level, and the activation of the $\alpha-2$ receptor in the locus ceruleus causes the analgesic and sedative effect [6].

Other than the central analgesic effect [6], the mechanism by which a-2 agonists extend the duration of local anesthetics as an adjuvant can be explained by the vasoconstriction effect in the periphery from $\alpha-2$ adrenergic receptors [7-10]. There is also the possibility that these drugs directly affect the periphery nerves $[11,12]$.

Postsynaptic $\alpha 1$ and $\alpha-2$ adrenergic receptors both exist in 
vessels, but their distribution differs according to the type of artery or vein. Vasoconstriction from the $\alpha-2$ adrenergic receptor can be stronger than that from the $\alpha 1$ receptor depending on the circumstances $[8,9]$. Talke et al. reported that arterial administration of clonidine caused vasodilation in an arm where sympathetic nerve activity had not been blocked $[7,10]$, and arterial administration of dexmedetomidine caused vasoconstriction in subjects whose sympathetic nerves were blocked or weakened through brachial plexus block or general anesthesia [7]. Although our study identified no clear effect of dexmedetomidine administered during brachial plexus block on vascular tone, the possibility of a vasoconstriction effect caused by $\alpha-2$ adrenergic receptors can be presumed. Gaumann et al. [21] compared $150 \mu \mathrm{g}$ of clonidine and $200 \mu \mathrm{g}$ of epinephrine as an adjuvant to $1 \%$ lidocaine in brachial plexus block to measure the duration of nerve block and the blood concentration of lidocaine. They found no difference in the duration of nerve block, but there was a difference in the blood concentration of lidocaine, and clonidine was reported to have no local vasoconstriction effect. However, no studies have yet measured the blood concentration of local anesthesia using dexmedetomidine as an adjuvant.

Concerning direct effects on peripheral nerves, Kosugi et al. [11] studied the effect of $\alpha-2$ agonists, including dexmedetomidine, tetracaine, oxymetazoline, and clonidine, and $\alpha-2$ blocker (atipamezole) on the compound action potentials (CAPs) in the sciatic nerve of a frog. They reported that, regardless of the $\alpha-2$ receptors, CAPs were repressed by the $\alpha-2$ agonists, which had direct blocking effects on nerve transmission. Brummett et al. [12], conducting sciatic nerve block in a mouse, administered dexmedetomidine as an adjuvant to ropivacaine; the authors reported that dexmedetomidine blocked the hyperpolarizationactivated cation current (Ih current) and extended the duration of nerve block. The Ih current plays an important role in returning the peripheral nerves to the resting potential, and blocking of the Ih current extends the hyperpolarization of the nerves. As this effect is especially evident in unmyelinated $C$ fibers (pain) compared to A a fibers (motor), the Ih current block is reported to be more effective in blocking pain nerves than in blocking motor nerves [22].

Our research used a dosage of $1 \mu \mathrm{g} / \mathrm{kg}$, which is the loading dose when IV administering dexmedetomidine for sedation purposes for 10 minutes. Thus, it is safe in IV sedation [23]. In previous studies in which it was used as an adjuvant in peripheral nerve block, it showed sedative effects such as symptoms of bradycardia and hypotension, but other complications were not reported [15-17]. Regarding nerve toxicity, dexmedetomidine did not damage the axon or myelin in animal experiments that used high doses $(25-40 \mu \mathrm{g} / \mathrm{kg})$, and it was even reported to reduce the acute perineural inflammation caused by bupivacaine [4].

Recently, the method of ultrasound-guided regional anesthesia has been accepted as the "gold standard" for reducing the amount of local anesthetic [24,25], and one limitation of our research is that we used a nerve stimulator. Successful nerve block was achieved in all patients, however, and considering that there was no effect on the onset time, the use of a nerve stimulator is not thought to have had an effect on the primary outcome, the duration of nerve block.

In our research, $1 \mu \mathrm{g} / \mathrm{kg}$ of dexmedetomidine extended the duration of sensory and motor block to a similar degree compared to epinephrine $200 \mu \mathrm{g}$ when administered around the nerve with local anesthetics. In contrast to epinephrine, it also decreased the heart rate, and there was a sedative effect without administering other sedative drugs.

In conclusion, dexmedetomidine was similar to epinephrine in its effect on extending the duration of nerve block and postoperative analgesia. However, because epinephrine and dexmedetomidine have opposite effects on heart rate, dexmedetomidine is considered to be a good alternative as an adjuvant to local anesthesia in patients in whom epinephrine must be used with caution.

\section{Acknowledgments}

This work is supported by Inha University.

\section{References}

1. Gerlach AT, Dasta JF. Dexmedetomidine: an updated review. Ann Pharmacother 2007; 41: 245-52.

2. McCutcheon CA, Orme RM, Scott DA, Davies MJ, McGlade DP. A comparison of dexmedetomidine versus conventional therapy for sedation and hemodynamic control during carotid endarterectomy performed under regional anesthesia. Anesth Analg 2006; $102: 668-75$.

3. Ramsay MA, Luterman DL. Dexmedetomidine as a total intravenous anesthetic agent. Anesthesiology 2004; 101: 787-90.

4. Brummett CM, Norat MA, Palmisano JM, Lydic R. Perineural administration of dexmedetomidine in combination with bupivacaine enhances sensory and motor blockade in sciatic nerve block without inducing neurotoxicity in rat. Anesthesiology 2008; 109: 502-11.

5. Esmaoglu A, Yegenoglu F, Akin A, Turk CY. Dexmedetomidine added to levobupivacaine prolongs axillary brachial plexus block. Anesth Analg 2010; 111: 1548-51. 
6. Guo TZ, Jiang JY, Buttermann AE, Maze M. Dexmedetomidine injection into the locus ceruleus produces antinociception. Anesthesiology 1996; 84: 873-81.

7. Talke P, Lobo E, Brown R. Systemically administered alpha2-agonist-induced peripheral vasoconstriction in humans. Anesthesiology 2003; 99: 65-70.

8. Ruffolo RR Jr. Distribution and fuction of peripheral alpha-adrenoreceptors in the cardiovascular system. Pharmacol Biochem Behav 1985; 22: 827-33.

9. Flavahan NA, Cooke JP, Shepherd JT, Vanhoutte PM. Human postjunctional alpha-1 and alpha-2 adrenoreceptors: differential distribution in arteries of the limbs. J Pharmacol Exp Ther 1987; 241: 361-5.

10. Talke PO, Lobo EP, Brown R, Richardson CA. Clonidine-induced vasoconstriction in awake volunteer. Anesth Analg 2001; 93: 271-6.

11. Kosugi T, Mizuta K, Fujita T, Nakashima M, Kumamoto E. High concentrations of dexmedetomidine inhibit compound action potential in frog sciatic nerve without alpha(2) adrenoreceptor activation. Br J Pharmacol 2010; 160: 1662-76.

12. Brummett CM, Hong EK, Janda AM, Amodeo FS, Lydic R. Perineural dexmedetomidine added to ropivacaine for sciatic nerve block in rats prolongs the duration of analgesia by blocking the hyperpolarization-activated cation current. Anesthesiology 2011; 115: 836-43.

13. Laurance EM, Gregory TT. Properties, absorption and disposition of local anesthetic agents. In: Neural blockadein clinical anesthesia and management of pain medicine. 4th ed. Edited by Cousins MJ, Bridenbaugh PO: Philadelphia, Lippincott Williams \& Wilkins. 2009 , p 70.

14. Butterworth JF. Clinical pharmacology of local anesthetic agents. In: Neural blockade in clinical anesthesia and management of pain medicine. 4th ed. Edited by Cousins MJ, Bridenbaugh PO: Philadelphia, Lippincott Williams \& Wilkins. 2009, pp 96-113.

15. Rancourt MP, Albert NT, Côté M, Létourneau DR, Bernard PM. Posterior tibial nerve sensory blockade duration prolonged by adding dexmedetomidine to ropivacaine. Anesth Analg 2012; 115: 958-62.

16. Swami SS, Keniya VM, Ladi SD, Rao R. Comparison of dexmedetomidine and clonidine ( $a 2$ agonist drugs) as an adjuvant to local anaesthesia in supraclavicular brachial plexus block: A randomized double blind prospective study. Indian J Anaesth 2012; 56: 243-9.

17. Obayah GM, Refaie R, Aboushanab O, Ibraheem N, Abdelazees M. Addition of dexmedetomidine to bupivacaine for greater palatine nerve block prolongs postoperative analgesia after cleft palate repair. Eur J Anaesthesiol 2010; 27: 280-4.

18. Yang CW, Kwon HU, Cho CK, Jung SM, Kang PS, Park ES, et al. A comparison of infraclavicular and supraclavicular approaches to the brachial plexus using neurostimulation. Korean J Anesthesiol 2010; 58: 260-6.

19. Marhofer D, Kettner SC, Marhofer P, Pils S, Weber M, Zeitlinger M. Dexmedetomidine as an adjuvant to ropivacaine prolongs peripheral nerve block: a volunteer study. Br J Anaesth 2013; 110: 438-42.

20. Han JU, Jung JK, Lim HK, Lee JH, Seo CH, Shinn HK. Usefulness of ultrasound-guided infraclavicular brachial plexus block: a comparison with nerve stimulation method. Korean J Anesthesiol 2008; 55: 436-440.

21. Gaumann D, Forster A, Griessen M, Habre W, Poinsot O, Della Santa D. Comparison between clonidine and epinephrine admixture to lidocaine in brachial plexus block. Anesth Analg 1992; 75: 69-74.

22. Lönnqvist PA. Alpha-2 adrenoreceptor agonists as adjuvants to peripheral nerve blocks in children-is there a mechanism of action and should we use them? Paediatr Anaesth 2012; 22: 421-4.

23. Candiotti KA, Bergese SD, Bokesch PM, Feldman MA, Wisemandle W, Bekker AY. Monitored anesthesia care with dexmedetomidine: a prospective randomized, double-blind, multicenter trial. Anesth Analg 2010; 110: 47-56.

24. Marhofer P, Harrop-Griffiths W, Kettner SC, Kirchmair L. Fifteen years of ultrasound guidance in regional anaesthesia: part 1. Br J Anaesth 2010; 104: 538-46.

25. Marhofer P, Harrop-Griffiths W, Willschke H, Kirchmair L. Fifteen years of ultrasound guidance in regional anaesthesia: Part 2-recent developments in block techniques. Br J Anaesth 2010; 104: 673-83. 